This item was submitted to Loughborough's Research Repository by the author.

Items in Figshare are protected by copyright, with all rights reserved, unless otherwise indicated.

\title{
Thermal stress analysis of conductive adhesive joints
}

PLEASE CITE THE PUBLISHED VERSION

PUBLISHER

(C) IEEE

LICENCE

CC BY-NC-ND 4.0

\section{REPOSITORY RECORD}

Ogunjimi, Adebayo Oluyinka, David C. Whalley, and David J. Williams. 2019. "Thermal Stress Analysis of Conductive Adhesive Joints". figshare. https://hdl.handle.net/2134/3982. 
This item was submitted to Loughborough's Institutional Repository (https://dspace.lboro.ac.uk/) by the author and is made available under the following Creative Commons Licence conditions.

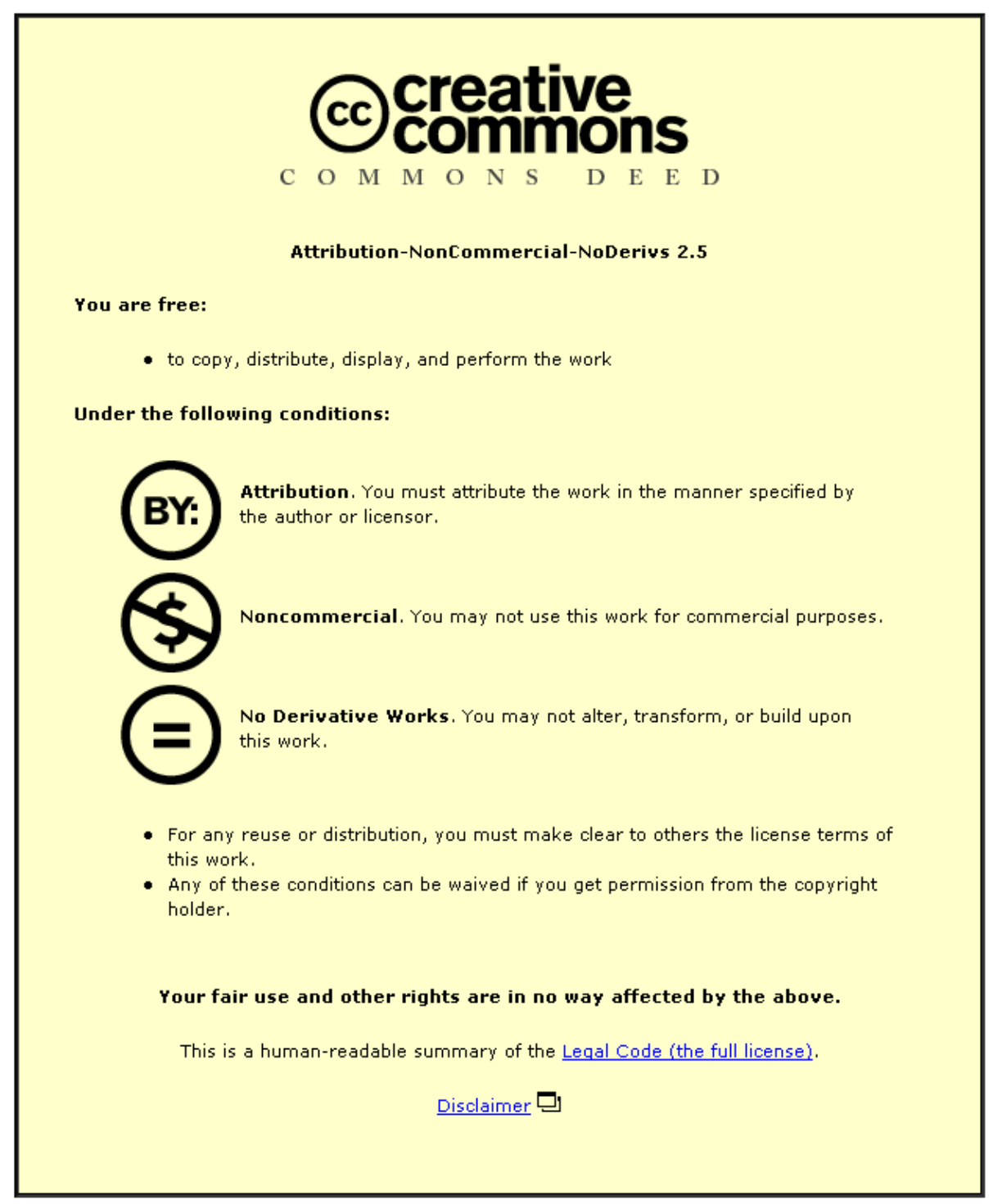

For the full text of this licence, please go to: http://creativecommons.org/licenses/by-nc-nd/2.5/ 


\title{
THERMAL STRESS ANALYSIS OF CONDUCTIVE ADHESIVE JOINTS
}

\author{
A.O. Ogunjimi, D.C. Whalley, D.J. Williams \\ Department of Manufacturing Engineering \\ Loughborough University of Technology \\ Loughborough, Leics. LE11 3TU
}

Abstract The effect of die geometry and the bond layer thickness on the stress distribution in a conductive die attach assembly was analysed using finite element models. Models used for the analysis were those of a freely deforming assembly i.e. not restrained by packaging. It was found that the thinner the bondline, the greater the stress in the joint. The level of stress in the joint remains approximately constant for die sizes greater than $(4 \times 4) \mathrm{mm}$ and a sawn through die was found to be much better for stress management.

\section{Introduction}

Conducting adhesives are currently being used for die-attach in a number of applications. The drive for high quality and reliable electronic interconnects calls for an understanding of the various parameters involved in the design and manufacture of such joints. The finite element method offers a valuable tool for analysis of such joints since features such as adhesive fillets and the precise geometry of the components of an assembly can be taken into consideration during modelling.

The adhesive is usually applied to the substrate by screen printing or syringing, components are then placed upon the adhesive and the adhesive cured by the application of heat in an oven or belt furnace. Such curing processes can lead to significant residual stress which may influence the manufactured quality of the joint and its subsequent reliability. The mechanical properties and curing temperature of the adhesive combined with the joint geometry are important in determining such stresses. This paper presents the result of a study of the effect of the die geometry and the bond layer thickness on the stress distribution in a conductive adhesive die attach assembly.

\section{Joint Geometry}

Examination of cross-sections through typical die attach assemblies, reveals two important features:

(1) The edge of the silicon die may have three types of geometry: straight edge (Fig.1a),undercut edge(Figure 1b), and bevelled edge (Figure 1c).

(2) The adhesive forms a triangular fillet around the base of the die.

Examination of micrographs also revealed that the bond-line thickness of the adhesive (although printed through a $50 \mu \mathrm{m}$ thick screen emulsion deposit) was, after placement and cure, about $34 \mu \mathrm{m}$. The adhesive fillet was found to rise to about $h / 4$ where $h$ is the height of the die and the fillet is approximately an isosceles triangle. The bevelled and undercut geometries observed resulted from the method of manufacture where the silicon wafers are scribed or partly sawn and then cleaved. For a silicon wafer with a 100 orientation (as in our specimens), it is expected that the cleavage after scribing or part-sawing perpendicular to the flat surface will reveal the 111 plane. Hence the side of the cleaved walls will be at $54.7^{\circ}$ to the flat surface.

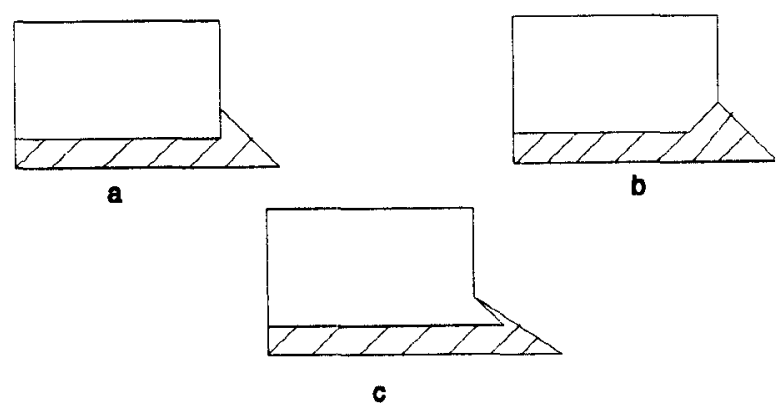

Figure 1: Observed Die Geometries

3. The Model

A bare silicon die and an alumina substrate bonded together by a high glass transition $\left(\mathrm{T}_{\varepsilon}\right)$ epoxy adhesive engineered for high temperature applications was modelled. A linear analysis of the thermally induced stress created by cooling the system from the curing temperature $\left(275^{\circ} \mathrm{C}\right.$ ) to ambient (taken as $25^{\circ} \mathrm{C}$ ) was performed.

The main assumptions used in the model are as follows:-

1. All material properties were considered to be linear ( i.e. stress relief due to plastic deformation of the adhesive was not taken into consideration).

2. The adhesive layer is homogeneous and void free.

3. The system is in equilibrium at the curing temperature (i.e. strain free). 
4. Isotropic material properties were assumed for silicon.

Three 3-Dimensional models of these observed joint geometries were built using the dimensions and material properties as shown above. Planes of symmetry were taken along the diagonal (z'y-plane) and the mid-plane (xy-plane). This use of symmetry reduces the model size by a factor of 8 . The fillet was modelled as an isosceles triangle of height $125 \mu \mathrm{m}$ and the die cleavage angles were $57.4^{\circ}$. The material properties used are shown in Table 1.

\begin{tabular}{|c|c|c|c|}
\hline & E(GPa) & $\alpha(100-6 / \mathrm{C})$ & $v$ \\
\hline Die & 190.00 & 3.06 & 0.27 \\
\hline Adhesive & 4.65 & $55.87^{* *}$ & 0.35 \\
\hline Substrate & 380.00 & 7.80 & 0.34 \\
\hline
\end{tabular}

E - Young's Modulus of Elasticity

$\alpha$ - Thermal Coefficient of Expansion

$v$ - Poisson Ratio

** Average over the temperature range considered

Table 1: Materials Property Data

It was reported in an earlier paper [1], that an axisymmetric model is a good approximation for the geometry of the die attach assembly. Axisymmetric models were therefore used in this work to investigate the effect of bond-line thickness and die size.

Five axisymmetric models with varying bond-line thickness $(10 \mu \mathrm{m}$ to $50 \mu \mathrm{m})$ were analysed for the sensitivity of the assembly to bond-line thickness. Similarly five models ranging from $2 \times 2 \mathrm{~mm}$ to $10 \times 10 \mathrm{~mm}$ were used to investigate the sensitivity to die size. Figure 2 shows a plan view of the die attach assembly and indicates the axisymmetric approximation used.

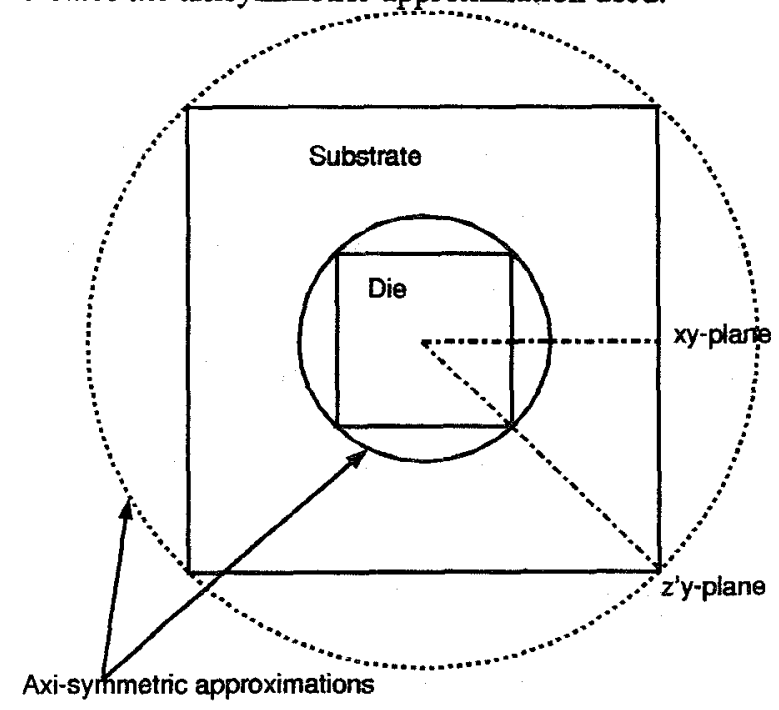

Figure 2: Plan view of the Die-Attach assembly

\section{Results and Discussion}

There are four significant regions of interest in the die-attach assembly modelled:

a. The surface of the die; to predict whether stresses are high enough to cause cracking.

b. The edge of the die; to investigate the possibility of cracking.

c. The two interfaces of the adhesive; to check for the possibility of failure by peeling.

d. In the bulk of the adhesive to check for the likelihood of plastic yielding of the resin.

The predicted stress level in the die can be compared with the ultimate strength of silicon in order to determine the likelihood of failure. There is no single criterion for evaluating peel at the interfaces unless practical experiments are performed for the particular assembly and materials in question. The effect of die size and bond-line thickness was evaluated using the stress level in the die as this gave a more easily comparable set of data. The four areas outlined above were examined for each die geometry modelled. It should be noted that the substrate in this analysis is allowed to deform freely without the constraints of any form of packaging as might occur in a real product. The situation described above assumes the manufacturing situation in which the product is not yet packaged, therefore it may not apply to a product in service in which the substrate may be constrained to remain flat.

As part of the efforts to validate the models, a similar assembly was cured while observing the strain fringes using Electronic Speckle Pattern Interferometry (ESPI)[2]. The out of plane gross displacement of the assembly observed by this method was found to be $80 \mu \mathrm{m}$ with an $18 \%^{\dagger}$ error band. The 3-D model for the straight edged die however predicted $66 \mu \mathrm{m}$ out of plane displacement between the centre of the substrate and its corner. The correlation between this experiment and the analysis results shows a good degree of confidence in the modelling effort.

\subsection{Sensitivity to Bond-line Thickness}

Figure 3 shows the peak maximum principal stress on the surface of the die for the different bondline thicknesses. It is apparent from the graph that the thinner the bondline the greater the stress on the surface of the die. The stresses shown are those expected along the mid-plane of the assembly. A higher stress level of about 1.6 to 1.85 times those shown in Figure 3 is expected along the diagonal [1]. It can also be seen that the rate of change of stress begins to decrease above a bondline thickness of $20 \mu \mathrm{m}$ and is actually lowest between 30 and $40 \mu \mathrm{m}$. The differences in stress

"This relatively large value is typical of error arising from manually counting the number of interference fringes 
level above the $30 \mu \mathrm{m}$ thickness could include an artifact of mesh fineness. It may therefore be concluded that, for stress management, the bondline thickness should be greater than $30 \mu \mathrm{m}$.

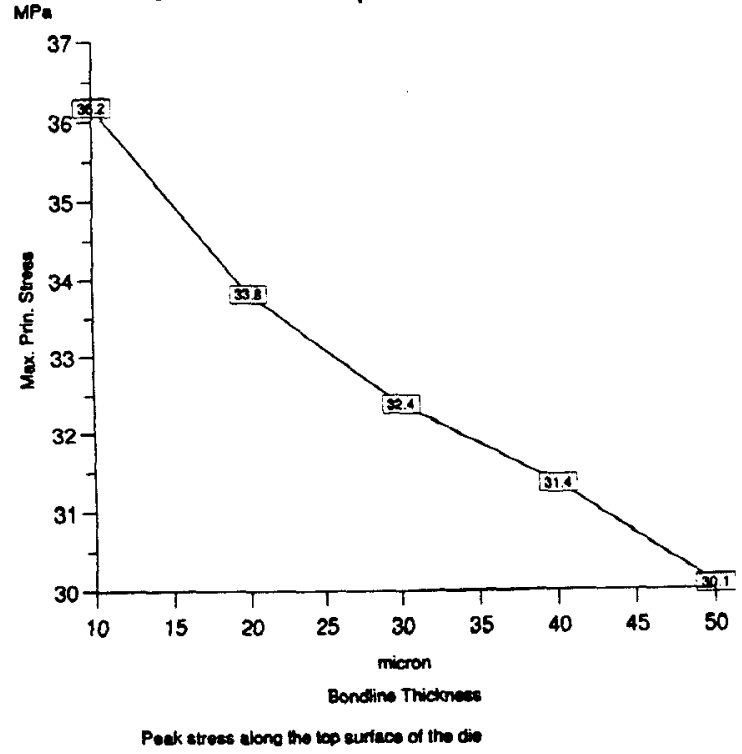

Figure 3 :Sensitivity to Bond-line thickness

Examination of the stress normal (in the $Y$ direction) to the interfaces(Figures 4 and 5 ) reveals that there is very little variation in the level of stress for the different bondline thicknesses.

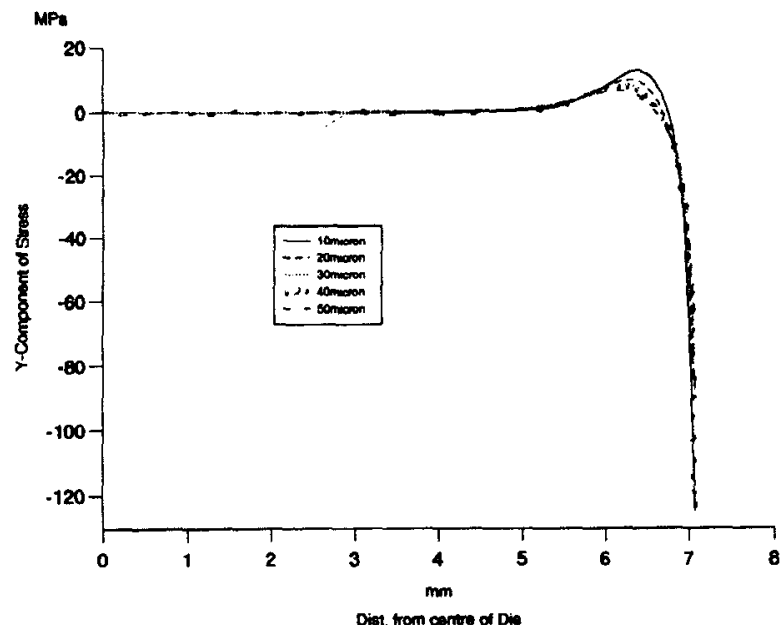

Figure 4: Stress on the Die-Adhesive Interface (sensitivity to bond-line thickness)

However, figure 5 particularly shows that the tensile stress observed in the interfaces have some sensitivity to bondline thickness, but this effect is very small in comparison with the compressive stress at the edge of the interface.

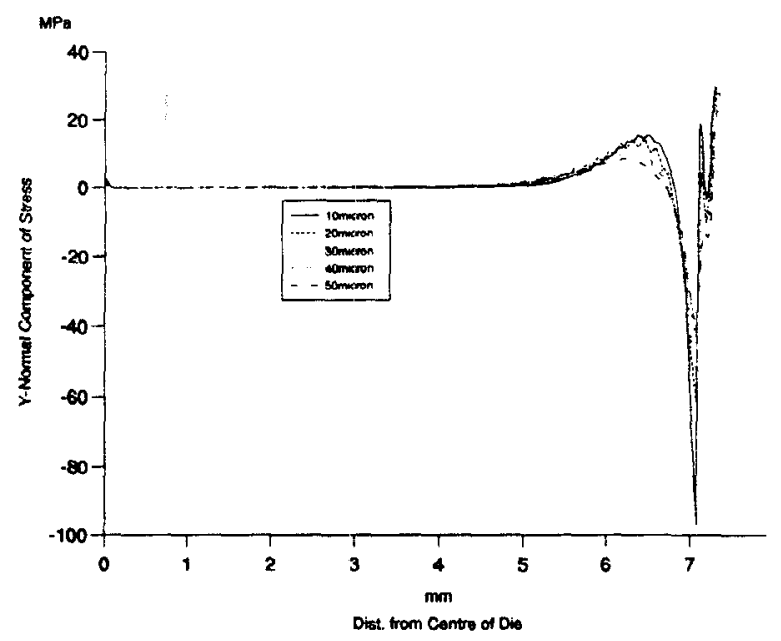

Figure 5: Stress on the Adhesive-Substrate Interface (sensitivity to bond-line thickness)

\subsection{Sensitivity to Die Sizes}

A plot of the peak stress along the die surface for different square die sizes ranging from $2 \times 2 \mathrm{~mm}$ to $10 \times 10 \mathrm{~mm}$ (Figure 6) reveals that the maximum stress to be expected on the xy-plane occurred with the $4 \mathrm{~mm}$ square die. It can be seen from the graph that the peak stress occurs closer to the perimeter of the die therefore the effect of the peak stress over the whole die seems to be balanced by a bigger passive region in the larger dies. The graph therefore presents a situation where above a certain size the peak stress does not increase with increase in die size. The small differences in peak stress predicted for die sizes greater than $4 \mathrm{~mm}$ square (observed from the graphs) is not significant and could have resulted from the level of refinement of the mesh.

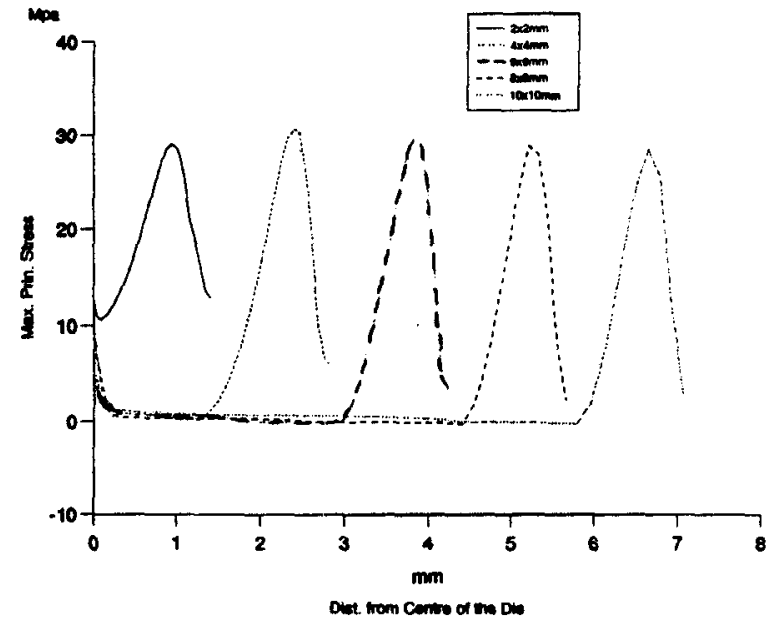

Figure 6: Sensitivity to Die sizes

\subsection{Sensitivity to Die geometry}

A comparison of the predicted stress level on the surface of the die (Figure 7) for the different die geometries indicates that the maximum stress level oc- 
curred in the die with the undercut edge. The bevellededge die has the lowest level of stress. However, it should be borne in mind that a bevelled and an undercut edge will most likely occur at opposite ends of the same die. This indicates that a sawn through die is better than scribed-cleaved die for stress management.

A graph of the stress on the edge of the die, Figure 8 , shows that the maximum stress occurred in the undercut edge die, followed by the straight edge and finally the bevelled edge die. The stress level observed, when compared with the ultimate tensile strength of silicon(horizontal line on the graph), indicates that there is only a small margin of safety for the undercut geometry. It was also observed that the the peak stress on the edges did not occur at the start of the fillet $(0.175 \mathrm{~mm})$ which shows that the stress resulted from the geometry of the die itself. Furthermore, variation in stress distribution resulting from differences in geometry is observed in the fact that some of the edges resulted in compressive stresses and the peak stresses occurred at different heights for different geometries and planes.

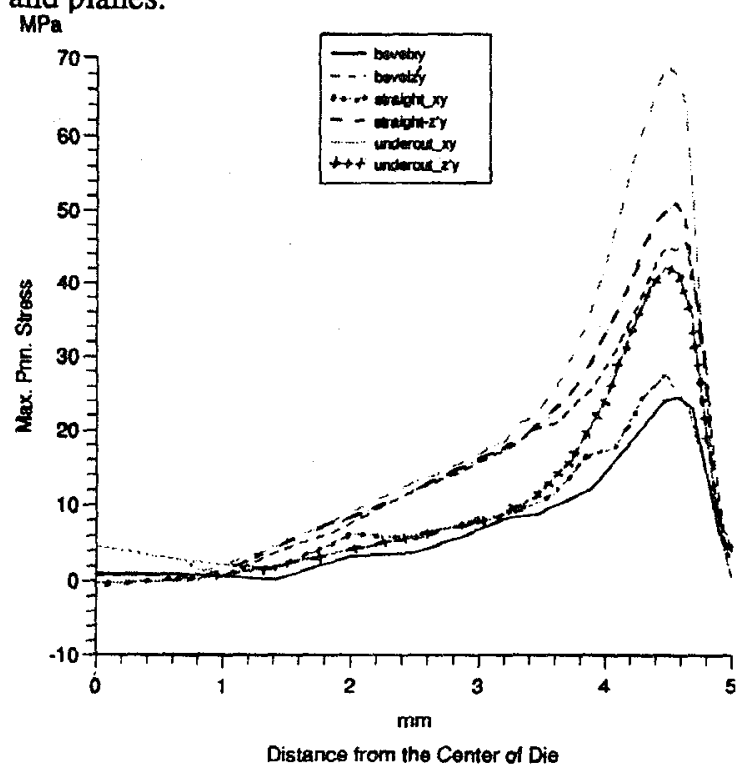

Figure 7: Stress on the surface of the Die

The graphs of stresses at the interfaces (Figures 9 and 10) show very little difference in stress level between the three different geometries. Differences are however obvious in the level of stresses observed for the different planes. It was also noticed (as indicated for the undercut edge) that the maximum tensile stress normal to the interfaces occurred at the Die-Adhesive interface suggesting that peeling will probably initiate at this interface. It is also worth mentioning here that the stress on the Die-Adhesive interface plotted in Figure 9 is for the portion of the die resting vertically on the adhesive and not necessarily to the tip of the fillet

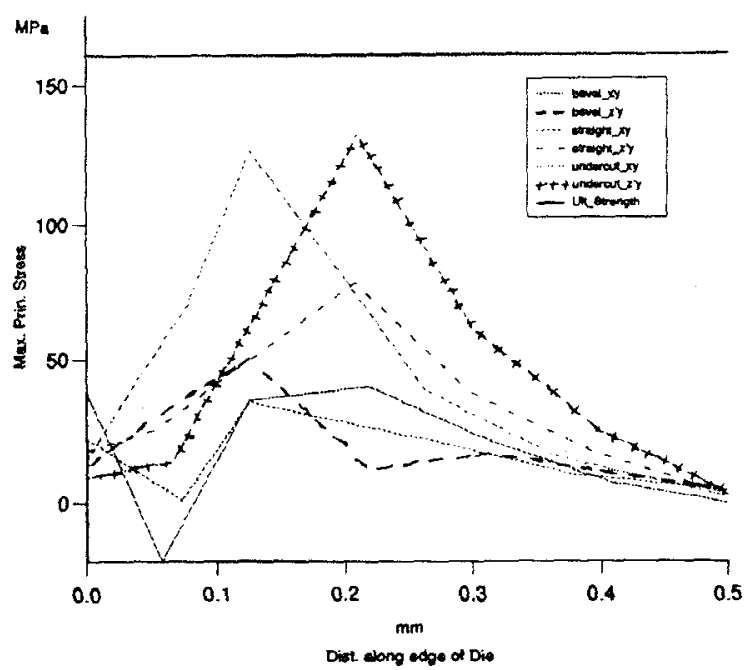

Figure 8: Stress on the edge of the Die

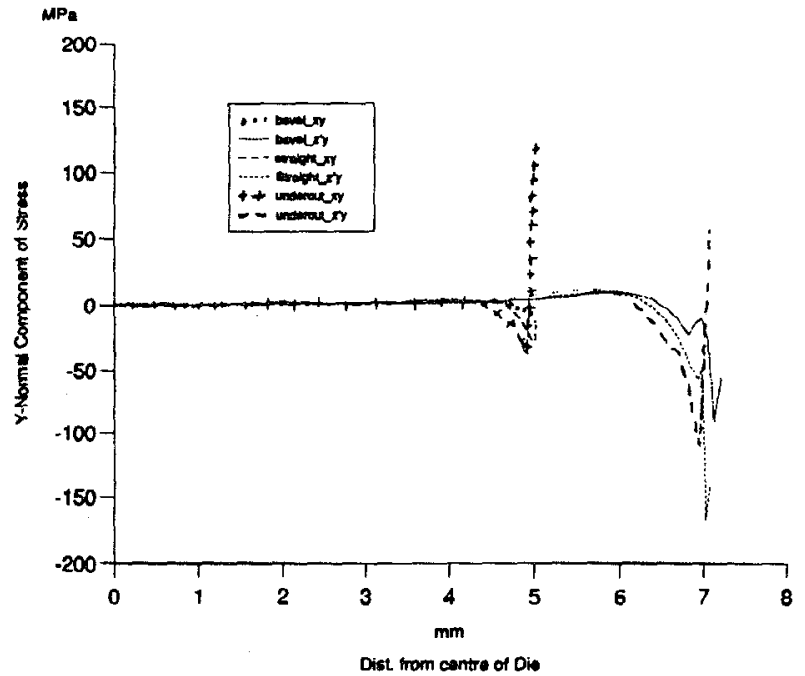

Figure 9: Stress on the Die-Adhesive Interface

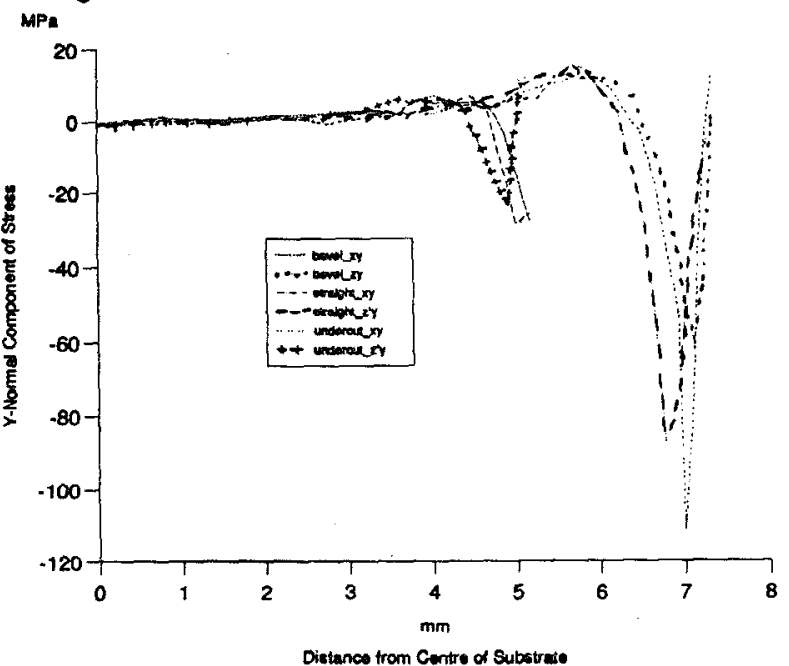

Figure 10: Stress on the Adhesive-Substrate Interface 
except for the die with the undercut edge. The observed stress curves at the interfaces are consistent with observations in other published works as noted by Kin. loch [3]. Some of the main points that emerged from previous contributions was that the in-plane normal stress in an adhesive joint is tensile in nature and are uniform near the interface and may be given by

$$
\sigma=\mathrm{E}_{\mathrm{a}} \Delta \alpha_{\mathrm{t}} \Delta \mathrm{T}
$$

where:-

$\mathrm{E}_{\mathrm{a}}=$ Modulus of Elasticity of the Adhesive;

$\Delta \alpha_{t}=$ Difference in linear thermal coeffiient of expansion between the adhesive and substrate;

$\Delta \mathrm{T}=$ Change in temperature between the stress free temperature and the temperature of interest.

This formula was proposed for structural adhesive joints in which the adherents are both made of the same materials. Furthermore, it gives an approximate value that takes no account of the geometry factor. Using this formula,the estimated tensile normal stress should have been $86 \mathrm{Mpa}$ compared with the $130 \mathrm{Mpa}$ predict ed by the finite element analysis.

It should be noted that the results presented in this paper are for models of a freely deforming assembly. The stress levels and perhaps the stress distribution may change when the assembly is packaged as constraints may be imposed by the packaging. Similarly, linear elastic properties have been assumed throughout the models so if plasticity or creep occur in the real materials the actual stress levels will be lower.

\section{Conclusions}

It has been shown in this paper that for a freely deforming conductive adhesive die attach assembly, the bondline thickness should be above $30 \mu \mathrm{m}$ for good stress management. There are indications to the fact that there is an increase in peak stress in the die with increasing die size up to about $4 \times 4 \mathrm{~mm}$ after which the level of stress remains approximately constant. Similarly, a sawn through die is much better for stress management.

\section{Acknowledgements}

The authors acknowledge the support of a consortium of industrial collaborators including Lucas Aerospace, Lucas Advanced Engineering Centre and Rolls Royce and the financial support of the ACME Directorate of SERC under grant GR/H21241. Our thanks to Mr. John Petzing of the Mechanical Engineering Department, Loughborough University of Technology, for performing the ESPI experiments.

\section{$\underline{\text { References }}$}

[1] A.O. Ogunjimi, D.C. Whalley and D.J. Williams, " A comparison of Modelling methods for Electronic Interconnect Structures" Proceedings of the IEEE Electronic Components and Technology Conference, June 1993

[2] C. Wykes, "Use of electronic speckle pattern interferometry (ESPI) in the measurement of static and dynamic surface displacements" Optical Engineering, May/June 1982 Vol.21 No.3 pp 400-406.

[3] A.J. Kinloch, Adhesion and Adhesives. New York: Chapman and Hall, 1987, ch. 6. 